\title{
Minimally Invasive Stabilization for Thoracolumbar Fractures
}

\author{
Yasin Sarıkafa ${ }^{1}$, Hikmet Demirkol ${ }^{1}$, Olgün Peker ${ }^{2}$ and Suat Erol Çelik ${ }^{3 *}$
}

${ }^{1}$ Attending neurosurgeon, Department of Neurosurgery, Okmeydanı Training and Research Hospital, Istanbul, Turkey

${ }^{2}$ Resident of Department of Neurosurgery, Okmeydan Training and Research Hospital, Istanbul, Turkey

${ }^{3}$ Associate professor of neurosurgery, Head of the Department of Neurosurgery, Okmeydani Training and Research Hospital, Istanbul, Turkey

\begin{abstract}
Minimally invasive approaches are becoming increasingly widespread due to numerous potential advantages (smaller scars, diminished local pain, reduced blood loss, reduced postoperative wound pain, shorter hospital stays) in spinal surgery. Nowadays, minimally invasive stabilization is more frequently used to treat some thoracolumbar fractures. The aim of this study is to explore the feasibility and effect of minimally invasive stabilization for the treatment of unstable thoracolumbar fractures without neurological impairment. From October 2011 to February 2012, 20 patients with thoracolumbar fracture who were treated with minimally invasive stabilization were included in this study. Charts and operative notes were analyzed for epidemiological data, injured segments, operative time, bleeding volume, mobilization interval, complications and lengths of stay. All patients were successfully managed with minimally invasive stabilization. There were 14 males and 6 females with a mean age of 33.75 years ranging from 18 to 59 years. The L1 vertebra was the most injured vertebral level (35\%), followed by T12 and L2. Mechanisms of injury included falling from a height (12 patients) and traffic accidents ( 8 patients). The average operative time was 72 minutes (range 60 to $122 \mathrm{~min}$ ). The average intraoperative blood loss was $80 \mathrm{ml}$ (range 50 to $270 \mathrm{ml}$ ). Minimally invasive instrumentation of the spine reduces intraoperative blood loss, soft tissue trauma, operative time, infection rates and hospital stay. Future developments in minimally invasive technology will lead to improved results with increased indications and applications.
\end{abstract}

Keywords: Minimally invasive; Thoracolumbar; Percutaneous; Pedicle screw; Spinal surgery

\section{Introduction}

Unstable thoracolumbar fractures are common spine injuries with increased mortality and morbidity. The management of such thoracolumbar fractures still remains controversial due to the numerous treatment modalities available. Conservative treatment (bed rest, brace, or cast) is highly demanding for the patient and is reserved for patients unsuitable for surgical intervention. It is well known that conservative management may lead to complications such as kyphosis with other deformities, pressure sores, and delayed neurological impairment $[1,2]$. Conservative treatment may also not be advisable in some cases due to accompanying cofactors such as multitrauma, obesity, and bronchopulmonary. Young patients are not good candidates for conservative treatment as they may not strictly follow bed rest or the hypoactive period.

Pedicle screw based open surgical instrumentation provides immediate spinal stability with rapid fusion and restores sagittal alignment, vertebral height, and canal dimension better than conservative management [3]. This conventional surgery may be an alternative to minimal invasive procedures but has significant morbidity due to high intraoperative blood loss, increased infection rates, and extensive dissection of the paraspinous muscles. The last may result in paraspinal muscle denervation or severe multifidus muscle atrophy that should be taken into consideration [4,5]. Minimally invasive stabilization may therefore be a better choice. Magerl was the first to introduce the technique of percutaneous lumbar pedicle screw fixation in 1984 [6]. The most important advantages of minimally invasive spinal surgery are the faster recovery with mobilization of the patient and decreased complications by minimizing iatrogenic tissue injury. Approach-related morbidity is significantly reduced thanks to the preservation of the normal anatomical structures while decreasing the incidence of delayed progressive deformity and degenerative changes [7]. This study introduces the application of minimally invasive stabilization and explores its feasibility in unstable thoracolumbar fractures.

\section{Materials and Methods}

A total of 20 patients with unstable thoracolumbar fracture who were treated with minimally invasive percutaneous stabilization from October 2011 to February 2012 were included in this study. Fractures with canal involvement requiring surgical decompression were not included. There were 14 male and 6 female patients. The mean age was 33.75 years (range 18 to 59). The fractures were classified according to Magerl [6] and the results are listed in Table 1. The L1 vertebra was the most injured vertebra (40\%) followed by T12 and L2. Mechanisms of injury included falling from a height (60\%) and traffic accidents (40\%). The demographic data are further presented in Table 2.

Preoperative plain X-ray films including supine lateral and AP views, computerized tomography (CT) scans with reconstruction of images and MRI images were obtained. Preoperative MRI showed canal dimensions, extradural bony structures, and soft tissue compression before surgery. MRI slices were especially important since cases with

\begin{tabular}{|c|c|}
\hline A3.1 & 4 \\
\hline A3.2 & 4 \\
\hline A3.3 & 9 \\
\hline B1 & 1 \\
\hline B2 & 2 \\
\hline
\end{tabular}

Table 1: Magerl classification of fractures.

*Corresponding author: Suat Erol Çelik, Associate Professor of Neurosurgery Head of the Department of Neurosurgery, Okmeydanı Training and Research Hospital, Istanbul, Turkey, Tel: +905323639455; Fax: +902122217763; E-mail: suaterolcelik@yahoo.com

Received May 26, 2013; Accepted June 26, 2013; Published June 28, 2013

Citation: Sarıkafa Y, Demirkol H, Peker O, Çelik SE (2013) Minimally Invasive Stabilization for Thoracolumbar Fractures. J Spine S5: 003. doi:10.4172/21657939.S5-003

Copyright: @ 2013 Sarıkafa Y, et al. This is an open-access article distributed under the terms of the Creative Commons Attribution License, which permits unrestricted use, distribution, and reproduction in any medium, provided the original author and source are credited. 
Citation: Sarıkafa Y, Demirkol H, Peker O, Çelik SE (2013) Minimally Invasive Stabilization for Thoracolumbar Fractures. J Spine S5: 003. doi:10.4172/2165-7939.S5-003

Page 2 of 3

\begin{tabular}{|l|l|}
\hline Characteristics & Patients \\
\hline Gender & \\
\hline Male & $14(\% 70)$ \\
\hline Female & $6(\% 30)$ \\
\hline Injured vertebra & \\
\hline L1 & $8(\% 40)$ \\
\hline T12 & $7(\% 35)$ \\
\hline L2 & $5(\% 25)$ \\
\hline Mechanism of Injury & \\
\hline Fall & $12(\% 60)$ \\
\hline Traffic Accidents & $8(\% 40)$ \\
\hline
\end{tabular}

Table 2: Demographic data of patients.

severe canal compromise or extradural soft tissue compression were switched to open surgery.

\section{Operative procedure}

After carefully positioning the patient on the table at the neutral prone position, the chest and pelvis were supported by silicone pads. The pedicles of the vertebral bodies identified with the tip of the Jamshidi needles under fluoroscopy control. A small skin incision was performed just $1 \mathrm{~cm}$ lateral of the projection of the pedicles. Lateralization of the incision was required to advance the screw into the vertebral body to the mediolateral angle. The $\mathrm{K}$-wire was inserted into the vertebral body and biplanar fluoroscopic control was performed. Paravertebral musculature was carefully dissected by advancing dilatation cannulas (Figure 1). A tap screw was inserted into the vertebra over the K-wire to prepare the vertebra body. After tapping of the corpus, pedicle screws were inserted with locked working cannulas on the K-wire under fluoroscopic control. Generally a total of 8 screws were inserted for each case to provide sagittal balance (Figure 2). Two rods with appropriate length were bent to achieve appropriate kyphosis and lordosis prior to insertion. After the insertion of rods under the fascia, screws were tightened inside the working cannulas.

Supine lateral and AP plain fluoroscopy were performed in the operating room, other diagnostics such as CT and MRI scans were obtained immediately after surgery. The postop scans were used to check the screw placement accuracy, restoration of the sagittal balance, and canal diameter (Figure 3). All cases were followed at regular intervals to check the postoperative vertebral fusion of the fracture level.

\section{Results}

All patients had uneventful postoperative recovery. Radiological examinations confirmed satisfactory pedicle engagement of all screws, good reconstruction of sagittal balance, and restoration of canal diameters. No complication was reported related to the surgical technique. The average operative time was 72 minutes (range 60 to 122 $\mathrm{min}$ ). The median intraoperative blood loss was $80 \mathrm{ml}$ (range $50-270$ $\mathrm{ml}$ ). The average length of stay was 3.5 days (range 2 to 8 days). All patients could be ambulated on the postoperative first day with an external brace. The patients could be discharged from the hospital on the $3^{\text {rd }}$ or 4 th day after the trauma. The median postoperative followup period is 14 months. All patients showed good skin healing with vertebral reconstruction without neural compromise.

\section{Discussion}

Percutaneous pedicle fixation of the traumatic spine is not new. Magerl introduced the first attempts in 1984. He used an external fixation device through the pedicles into the vertebral body for the treatment of unstable spine injuries and spinal osteomyelitis [6]. Later, Mathews and Long [8] used a fully percutaneous endoscope-assisted screw system in 1995 . They used a plate system instead of longitudinal

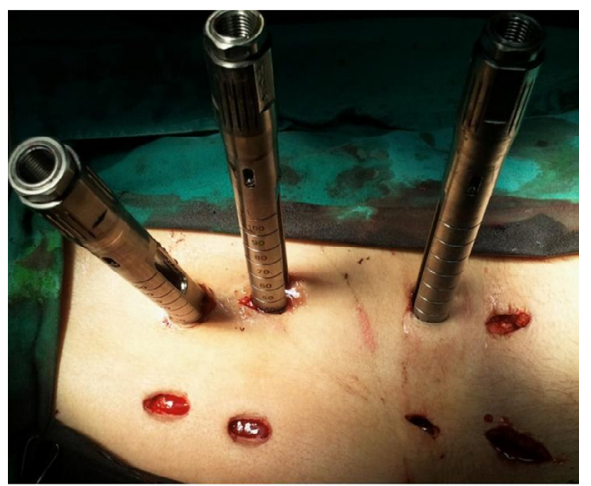

Figure 1: Tubes of the right side were removed with minimal skin incisions, while insertion tubes of the left side are still in position.



Figure 2: Satisfactory pedicle penetration of percutaneous screws on postoperative 3D computer tomography images; unstable burst fracture with no canal compromise can be seen at the middle bottom section.

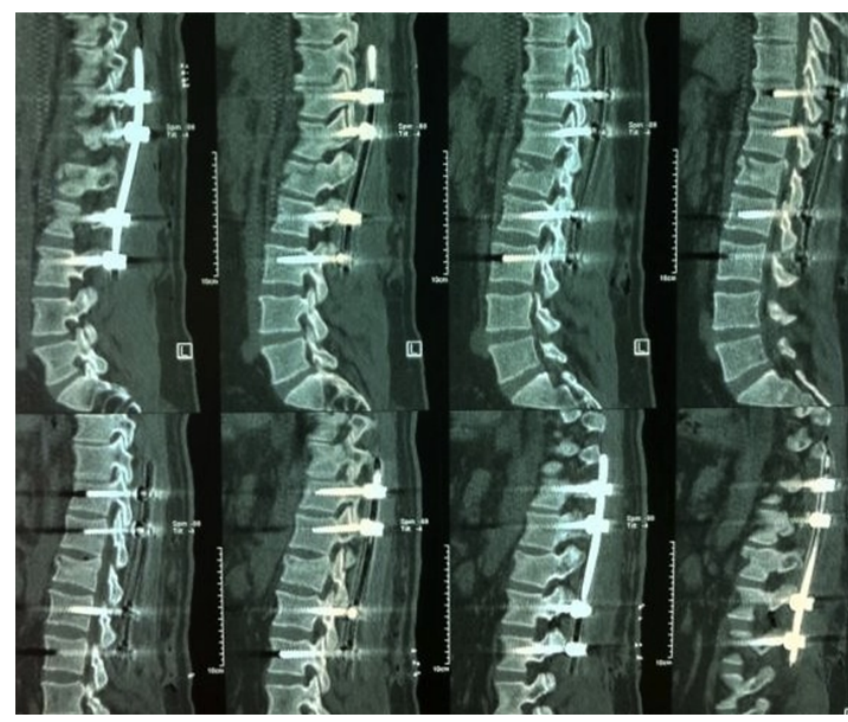

Figure 3: Sagittal 3D formatted computer tomography images show complete implant material with satisfactory correction of sagittal kypho/lordosis of the thoracolumbar region. 
rods. They also showed significant improvisation of the percutaneous system [8]. In 2000, Lowery and Kulkarini [9] described a more contemporary system. In their approach, insertion of the anterior interbody graft via laparoscopy was primarily performed, and the posterior percutaneous pedicle screws with rod connectors were then placed. The rod connectors were just under the fascia with this system. The results were satisfactory with a $61 \%$ fusion rate in 8 months [9]. One year later, a novel instrument (sextant) was presented by Foley KT and Gupta SK. Rod insertion and anchoring was much easier than the previous procedures during their initial experience with 12 patients. This device has gained universal acceptance and is still used in major spine centers [10]. The ultimate systems for percutaneous screw/rod insertion are more versatile. The head tube of every screw can facilitate rod insertion inside of tubes. Moreover, the instrumentation process can be increased more than two segments. The rod anchoring into the polyaxial screw head is also easier with rod persuaders.

Vertebral fractures have been studied in detail regarding the mechanism of occurrence and instability criteria. The majority of fractures at the thoracolumbar junction are between Th11 and L2. Magerl has subdivided vertebral body fractures into three main types [6]. Type A compression fractures include the lesions of the anterior spine. Type B includes transverse lesions involving both spinal columns. Type $\mathrm{C}$ includes rotational lesions involving both columns. Every type of fracture has three subcategories and burst fractures belong to class A3 according to this system of classification. They account $28 \%$ of all thoracolumbar spine injuries and are associated with an intact posterior ligamentous complex. The management of burst fractures with or without neurological deficit requires spinal stabilization, since such fractures are unstable. Otherwise, the occurrence of local kyphosis and the development of secondary neurological deficits also require surgical stabilization [11].

The type of surgical approach for traumatic thoracolumbar fractures remains controversial. Conventional open surgery is a well known and widely accepted method for the management of unstable thoracolumbar fractures but it has additional surgical risks, such as high infection rates, increased blood loss, more paraspinal muscle damage and prolonged operation time with more hospital stay. On the other hand, minimally invasive stabilization has potential benefits such as smaller scars, diminished local pain, reduced blood loss, reduced postoperative wound pain and therefore shortened hospital stays $[12,13]$. Patient outcomes are improved and costs are reduced, partly due to reduced hospital stays and recovery times. Average length of stay was only 3.5 days in our study. The decreased paraspinal muscle trauma and shorter surgical incision are advantageous in percutaneous pedicle screw placement. A lower infection rate was also encountered, particularly in obese patients with associated diabetes [14].

The two main disadvantages of percutaneous pedicle screw stabilization are reduced anatomical orientation in the first few cases (but the procedure can be learned quickly) and increased radiation exposure for both the surgery and anesthesia team.

The decreased accuracy of percutaneous pedicle screw placement has been investigated previously. The authors of a recent meta-analysis of 130 studies reported a $91.3 \%$ accuracy rate for placement of 34,107 screws [15]. Otherwise, increased accuracy rates for percutaneous pedicle screw placement have been shown with the use of threedimensional navigation systems [16].

In conclusion, percutaneous pedicle screw fixation represents a good alternative option over other surgical approaches or conservative treatment as a minimally invasive procedure in the treatment of thoracolumbar and lumbar spine fractures. A thorough knowledge of the surgical anatomy with experience in percutaneous procedures will increase the surgeon's ability to perform successful percutaneous pedicle screw instrumentation in routine practice.

\section{References}

1. Denis F, Armstrong GW, Searls K, Matta L (1984) Acute thoracolumbar burs fractures in the absence of neurologic deficit. A comparison between operative and nonoperative treatment. Clin Orthop Relat Res 142-149.

2. Domenicucci M, Preite R, Ramieri A, Ciappetta P, Delfini R, et al. (1996) Thoracolumbar fractures without neurosurgical involvement: surgical or conservative treatment? J Neurosurg Sci 40: 1-10.

3. Siebenga J, Leferink VJM, Segers MJ, Elzinga MJ, Bakker FJ, Haarman HJ, Rommens PM (2006) Treatment of traumatic thoracolumbar spine fractures: a multicenter prospective randomized study of operative versus nonsurgical treatment. Spine 31: 2881-2890.

4. Thomsen K, Christensen FB, Eiskjaer SP, Hansen ES, Fruensgaard S, et al. (1997) Volvo Award winner in clinical studies: the effect of pedicle screw instrumentation on functional outcome and fusion rates in posterolateral spinal fusion. A prospective, randomized, clinical study. Spine 22: 2813-2822.

5. Weber BR, Grob D, Dvorák J, Müntener M (1997) Posterior surgical approach to the lumbar spine and its effect on the multifidus muscle. Spine (Phila Pa 1976) 22: 1765-1772.

6. Magerl FP (1984) Stabilization of the lower thoracic and lumbar spine with external skeletal fixation. Clin Orthop Relat Res : 125-141.

7. Kim DY, Lee SH, Chung SK, Lee HY (2005) Comparison of multifidus muscle atrophy and trunk extension muscle strength: percutaneous versus open pedicle screw fixation. Spine (Phila Pa 1976) 30: 123-129.

8. Mathews $\mathrm{HH}$, Long $\mathrm{BH}$ (1995) Endoscopy assisted percutaneous anterior interbody fusion with supracutaneous suprafascial internal fixation: evolution of technique and surgical considerations. Orthop Int Ed. 3: 496-500.

9. Lowery GL, Kulkarni SS (2000) Posterior percutaneous spine instrumentation. Eur Spine J 9 Suppl 1: S126-130.

10. Kevin FT, Gupta SK, Justis JR, Sherman MC (2001) Percutaneous pedicle screw-rod fixation of the lumbar spine. Neurosurg Focus 10: E10.

11. Fuentes S, Blondel B, Metellus P, Gaudart J, Adetchessi T, et al. (2010) Percutaneous kyphoplasty and pedicle screw fixation for the management of thoraco-lumbar burst fractures. Eur Spine J 19: 1281-1287.

12. Tian W, Han X, He D, Liu B, Li Q, et al. (2011) The comparison of computer assisted minimally invasive spine surgery and traditional open treatment for thoracolumbar fractures. Zhonghua Wai Ke Za Zhi 49: 1061-1066.

13. Wild MH, Glees M, Plieschnegger C, Wenda K (2007) Five-year followup examination after purely minimally invasive posterior stabilization of thoracolumbar fractures: a comparison of minimally invasive percutaneously and conventionally open treated patients. Arch Orthop Trauma Surg 127: 335343.

14. Park Y, Ha JW, Lee YT, Sung NY (2011) Percutaneous placement of pedicle screws in overweight and obese patients. Spine J 11: 919-924.

15. Kosmopoulos V, Schizas C (2007) Pedicle screw placement accuracy: a metaanalysis. Spine (Phila Pa 1976) 32: E111-120

16. Fraser J, Gebhard H, Irie D, Parikh K, Harti R (2010) Iso-C/3-dimensional neuronavigation versus conventional fluoroscopy for minimally invasive pedicle screw placement in lumbar fusion. Minim Invasive Neurosurg 53: 184-190. 